\title{
HR PROFESSIONAL DEVELOPMENT: CREATING THE FUTURE CREATORS AT THE UNIVERSITY OF MICHIGAN BUSINESS SCHOOL
}

\author{
Wayne Brockbank, Dave Ulrich, and Richard W. Beatty
}

This article focuses on the development of mid- to senior-level HR professionals through a public program offered at the U niversity of M ichigan B usiness School. We suggest that developing $\mathrm{HR}$ professionals requires a theory of competencies about what $\mathrm{HR}$ professionals must know and do and a development experience based on those competencies. We highlight how we have created a competency model over the last decade and designed our HR executive programs to deliver against this model. We also show the pedagogical techniques used to deliver these competencies. (c) 1999 John Wiley \& Sons, Inc.

\section{Introduction}

For human resources (HR) to be a profession, those working in the discipline must master a set of competencies. Professions are characterized by unique knowledge and abilities; $\mathrm{HR}$ is no different. M astery of $\mathrm{HR}$ knowledge comes from knowing the concepts, language, logic, research, and practices of H R. M astery of abilities comes from being able to apply that knowledge to specific business settings. Attorneys work to master the canon of knowledge in case law, then demonstrate that knowledge as they offer specific legal advice. Physicians master the knowledge required by their specialty, then apply that knowledge to each patient's unique conditions.

In the executive programs at the U niversity of M ichigan Business School, we have worked to define the competencies and development experiences required of $\mathrm{HR}$ professionals. While our executive education offerings provide development opportunities for HR professionals at all levels, this article focuses on our approach to mid-career and senior-level HR professional development. We believe that in the face of increasingly turbulent business dynamics, this audience plays a key role in adapting the $\mathrm{HR}$ profession to these business challenges and requires continual professional development. M ichigan's HR Executive Programs have targeted both $H R$ professionals wanting to upgrade their skills and new entrants to the senior ranks of the $H R$ profession coming from outside HR. In either case, our work is based on (1) a theory and point of view about what constitutes competencies for HR professionals and (2) an integrated set of developmental experiences that enhance the required competencies.

\section{H R C ompetencies}

\section{Theory of HR Competence}

Competencies represent who an individual is and what an individual knows and does (Boyatzis, 1982; Clark, 1990; C urry \& Wergin and Associates, 1993). If wise investments in $\mathrm{HR}$ practices such as staffing, training,
For human resources (HR) to be a profession, those working in the discipline must master a set of competencies. 


The third and
most extensive of
the HR
competency
surveys has been
conducted at the
University of
Michigan School
of Business in
three rounds over
a ten-year period
with the
involvement of
over $20,000 \mathrm{HR}$
and line
professionals.

communication, compensation, organization design, performance management, and culture change help a business reach strategic and financial goals, HR professionals must have knowledge and activate agendas to make strategy-H R linkages happen. Competent H R professionals will have the personal credibility coupled with knowledge and behaviors to ensure that $\mathrm{HR}$ practices align with and accomplish business outcomes.

M ost competence work has focused on leaders and general managers (Boyatzis, 1982), with efforts to specify HR competencies coming from interviews with executives within a firm or a limited set of firms (Yeung, Woolcock, \& Sullivan, 1996). While this research offers firm-specific advice and insights, it is not sufficient to build an overall architecture for HR competencies within the profession. Firms generally have idiosyncratic requirements for making strategy happen. Hence, while firm-specific studies may provide interesting cases, these case studies alone will not provide an overall theory of $\mathrm{HR}$ competencies for the profession.

Three large-scale HR competency studies have been conducted. First, in collaboration with IBM , Towers Perrin (IBM /Towers-Perrin, 1991) surveyed 3,000 HR professionals, consultants, line executives, and academicians about a broad range of $\mathrm{HR}$ issues. The competency portion of this work revealed that line executives indicated computer literacy as the most critical H R competence; faculty wanted $\mathrm{HR}$ professionals to demonstrate broad knowledge of and a vision for $\mathrm{HR}$; consultants suggested anticipating the effects of change was most important; and $H R$ executives proposed educating and influencing line managers as the most critical competence.

Second, The Society of Human Resource $M$ anagement (SHRM) Foundation recently commissioned a study of future-oriented competencies of HR professionals (Schoonover, 1998). Based on data from 300 HR professionals in different industries and varying company size, this study found that a set of core competencies around leadership, management, functional, and personal attributes needed to be augmented by level- and rolespecific competencies. With these competencies, HR professionals would improve traditional HR services while creating and implementing future H R methods.

The third and most extensive of the $H R$ competency surveys has been conducted at the U niversity of M ichigan School of Business in three rounds over a ten-year period with the involvement of over $20,000 \mathrm{HR}$ and line professionals. O ur work at $M$ ichigan between 1988 and 1998 has identified competencies for $H R$ professionals across $H R$ functional specialties, industries, firms, and time. Our intent has been to create an architecture for the competencies for the entire HR profession, not just for a single firm.

\section{M ichigan's H R C ompetency R esearch} (1988-1998)

We began the research in 1988 by scanning the literature on competencies required for HR professionals and other staff groups; examining specific firm case studies of $H R$ competencies; and performing a series of pilot studies to identify a set of knowledge, skills, and abilities that were expected of HR professionals. ${ }^{1}$ With this input, we performed cross-company research to assess how H R competencies might vary by industry, level, function, global region, and expectation. Our first round of data collection in 1988 had data from over 10,000 individuals in 91 firms (Ulrich, Yeung, \& B rockbank, 1989). While this survey resulted in findings beyond the scope of this article, we found that $\mathrm{HR}$ professionals had to demonstrate competencies in three domains: knowledge of business, delivery of H R practices, and ability to manage change; and that the ability to manage change was more important than business knowledge and delivery of $\mathrm{HR}$ practices combined.

After this first round, we continued to explore competencies for HR professionals through research within firms on a companyspecific basis. Based on this anecdotal work, we felt that the competencies for HR professionals had evolved. We completed a second wave of multiple company data collection in 1992-1993, with a focus on global firms, and had over 5,000 participants. The findings suggested that HR professionals needed to be more knowledgeable about financial management, external competitive and customer 
demands, and be able to work with line executives to send clear and consistent messages about the firm's goals and directions (UIrich, Brockbank, Yeung, \& Lake, 1995). We found that the highest performing firms reduced time and effort spent on HR transactional issues as they outsourced, automated, and reengineered their $\mathrm{HR}$ activities. Thus, the relative amount of time spent on strategic issues escalated while the transactional focus of the leading firms diminished (Yeung, Brockbank, \& U Irich, 1994).

In the 1997-1998 study, with another 5,000 participants, we found that two additional domains of $\mathrm{HR}$ competencies emerged as keys for the successful HR professional: culture management and personal credibility (B rockbank, Ulrich, \& James, 1997). ${ }^{2}$ Culture management deals with how HR professionals help firms create both new patterns of behavior and mindsets among employees and a collective identity for the firm. Personal credibility deals with the extent to which HR professionals embody the values of the firm and act with "attitude" (UIrich \& Eichinger, 1998) in dealing with $\mathrm{HR}$ issues.

This research continues to evolve as we explore what $\mathrm{HR}$ professionals must know and do to be effective. In our current research, we are defining what is required of the top $H R$ executive by identifying the firm's expectations of top HR executives in 23 firms. We are also continuing to study how firms set expectations for their HR functions and the HR professionals within those firms.

The competency work we have pursued sets a standard and defines expectations for $\mathrm{HR}$ professionals. Without these competencies, investing in the development of $\mathrm{HR}$ professionals is a random act and while $H R$ curriculum may be designed, it may not provide HR professionals with frameworks and/ or tools necessary to turn business goals into results through $\mathrm{HR}$ practices. With these competencies in mind, the development of $H R$ professionals may be integrated, focused, and result in the creation of a profession.

\section{D eveloping H R Professionals}

In our executive programs for $\mathrm{H} \mathrm{R}$ professionals, we have worked to create a curriculum based on competency theory and research. We realize that U niversity-based development programs are not the only way to build HR competencies for mid- and senior-level HR professionals and that job assignments, coaching, personal feedback, and in-company programs may also be used to improve HR competencies. The public-based U niversity program has some unique advantages, however, in the quest to develop HR professionals.

First, it brings together individuals from diverse backgrounds. In a typical program we have 40 to 45 participants, 25 to $30 \%$ from outside N orth America (Europe, Asia, Latin America, and Eastern Europe); multiple HR functional areas (e.g., generalist, senior specialists in training, compensation, or H R planning); multiple industries (e.g., banking, utilities, consumer, manufacturing, etc.); diverse backgrounds (some have spent their careers in $H R$; some are new; some have graduate degrees); and styles. Such diversity helps participants appreciate and learn from each other.

Second, while diverse, the participants self-select to a program with common themes and agendas. They are able to recognize that the ways in which HR helps accomplish strategy in financial services in B razil may have lessons for a union plant in Alabama. Such diverse backgrounds with similar interests allow for dialogue, sharing best practices, and insights not found in single-company programs.

Third, the public program allows for identifying and sharing best practices from nontraditional sources. For example, an HR executive from a E uropean airline working to frame culture change learns lessons from a participant in a high-tech firm in Silicon Valley. $M$ any participants find that among the most valuable takeaways from the program are the network of relationships with individuals in other companies.

\section{Overall Framework for M ichigan Programs}

We have four levels of programs, tailored to those at varying stages in their careers. The first two levels focus on technical expertise for $\mathrm{HR}$ functional areas such as interviewing, labor relations, training, career development,

\section{In our current research, we are defining what is required of the top HR executive by identifying the firm's expectations of top HR executives in 23 firms.}




\section{Content without process, however, would be like owning a roadmap that gives direction, but not having the ability to travel or be on the road.}

human resource planning, compensation, organization design, and managing change. The first-level program offers participants new to the specialty the basic principles of that specialty. The second-level program offers $H R$ professionals advanced training in the particular specialty. For example, the one-week Strategy H uman Resource Planning is targeted for senior HR professionals charged with creating an HR strategy for a plant, division, business unit, or corporation.

The third level of courses focuses on the generalist. This two-week course, called $\mathrm{Hu}$ man Resource Executive Program (HREP), is designed for $\mathrm{HR}$ professionals who have a generalist perspective in either a plant, division, or business unit or for senior specialists desiring a generalist framework. The fourth-level course, called Advanced Human Resource Executive Program (AHREP), focuses on the senior HR generalists in divisions and/or corporations and specialists creating strategies for their firms.

\section{Application of Competency M odels to} AHREP

In AHREP we translate our competency research into tools to build HR professionals. ${ }^{3}$ The competency work provides a roadmap for the content of the two-week experience. To help HR professionals know the business, we identify the questions, information, and ideas that $\mathrm{HR}$ executives must bring to business discussions. We help participants comprehend finance, marketing, strategy, and operations so that they add value in business dialogues. To master HR trends, faculty present theory and research, and participants share best practices in staffing, training, development, performance measurement, organization design, communication, rewards, measuring $\mathrm{H} \mathrm{R}$, and leadership. We also provide a disciplined process for turning strategy into HR practices. To make sense of a firm's culture or identity, we focus on how $\mathrm{HR}$ practices shape and are shaped by the mindset within a firm. We demonstrate the importance of mindset as an integrating mechanism for $\mathrm{HR}$ practices and help participants diagnose and create a desired mindset. We provide participants with tools for making change happen and the ability to apply these tools to business initiatives. Finally, we help participants recognize how to build personal credibility as they collaborate with external customers, line managers, and other HR professionals.

$\mathrm{HR}$ competency theory and research defines the content of AHREP. As we move through each day and module, participants are reminded that when they master the competencies, they will be able to know and do that which is required of $\mathrm{HR}$ professionals.

Content without process, however, would be like owning a roadmap that gives direction, but not having the ability to travel or be on the road. While we rely on the competency model for what we teach, we also invest in how we present, sequence, and deliver content for maximum impact. In AHREP, we have incorporated the following pedagogical techniques:

1. Application teams. In the first week, we invite participants to form teams to apply our methodology of turning strategy into H R priorities. Each team forms with five to seven participants who share a common business challenge (e.g., growth, globalization, mergers). The team then builds an HR strategy to respond to this challenge. This work occurs during the evenings of the first week, applying material taught during the day and culminating in a presentation on Saturday of how business challenges may be turned into HR priorities. Participants learn through the actual experience of turning strategy in $\mathrm{H} R$ practice and by observing other teams doing similar work with different business challenges. Each participant leaves with handouts and presentations on business challenges and how HR can respond. This material has served as task force input for many alumni who after the program face these challenges.

2. Integrated faculty. M any public programs suffer from what we call a "parade of stars" where faculty come to the program, present a canned lecture or case, then leave. Participants must integrate and apply the material. I A AHEP, we have three core faculty who teach $70 \%$ of the days during the two weeks, build on each other's materials, facilitate evening workshops, consult with participants on specific challenges, and ensure continuity and flow of the two-week 
experience. Inevitably, participants rate the "whole" program better than the "parts" (daily speakers) because of the integration generated by the core faculty. The other $30 \%$ of the program is taught by other faculty, each of whom is recognized as both a content expert on the topic and a world-class consultant who has implemented the ideas in multiple firms. Faculty who each teach with different styles, who respect each other, who know each other's work, and who build on the ideas of other faculty become an important feature of the development experience.

3. Faculty pedagogy. Each faculty member has a unique style. Some use cases, videos, lectures, workshops, group presentations, and other pedagogical techniques. While we do vary instruction technology, our rule of thumb is that 60 to $70 \%$ of class time is in faculty-led discussions or lectures; the remaining time is spent in small-group discussions or participant-led, best-practice sharing.

4. Sharing best practices. In two weeks, faculty cannot expect to cover all topics of interest to participants. We encourage participants to be involved in the learning experience by sharing their "best practices" in three ways. First, we have an "open learning" afternoon built into the second week of the program, by which time participants are suffused with faculty presentations. During this afternoon, participants pick the topics, and core faculty facilitate dialogue and the sharing of ideas among participants. For example, in a recent program, many participants wanted more information on leadership development, so the class engaged in an open forum to create a "L eadership Effectiveness and Assessment Device", a ten-item diagnostic to assess the quality of leadership development within a firm based on the class participants' experience. Second, during the second week, participants select evening sessions that are devoted to more detail and/or topics not fully covered during the day sessions. Third, participants fill out a brief survey of their interests and expertise so they can informally meet to share ideas. Conceptually, we make the participants learners by both receiving and giving.

5. Continually updating content. Just as the HR competence model has both stayed the same and evolved, so does what we teach. Some content is relatively stable and fixed (e.g., strategy-H R linkages) and taught as principles; other content varies depending on themes we hear from participants (e.g., assessment centers, shared services, measuring $H R$, high performing teams). We generally try to change the content about $25 \%$ per year. This requires core faculty who continually invest in learning and involving other faculty with new forms of expertise.

6. Attending to group and social issues. We know that each class of participants takes on a personality. To understand the dynamics and expectations of each class, we have developed a mid-program break. It is held in a core faculty member's home where participants are out of their dorm rooms, in a casual setting, and willing to offer feedback and advice on the course. This mid-program discussion allows faculty to adapt in week two to a particular classes' needs and helps prepare the participants for the second week of learning.

7. Concern with personal issues. Being away from office and home for two weeks is difficult for many. We build in time and instruction for fitness (access to university facilities and personal fitness programs for those interested), exercise (trainer available as requested), and social activities (sport events, movies, meals); and we work to maintain the physical facilities (rooms, meals, breaks, etc.) at a world-class standard.

8. Structured syntheses. We know that in any two-week program, more material is covered than can be absorbed. We help participants synthesize the first week on the following Saturday by creating a set of criteria for effective HR based on what was presented during the week. This class activity ends the week with participants recognizing that they have redefined their views of what makes effective HR. Each participant may then rate his/her firm and him/ herself against these criteria as a way to demonstrate learning from week one. At the end of week two, we have created the "elevator speech" where participants synthesize their learning into one or two key questions they can share with their boss, peers, or subordinates when they return home and "get on the elevator together". 
Our intent is that participants leave the course feeling that the overall experience may have confirmed what they know or may have challenged what they know with what they need to know.
By depending on and always improving these process principles, we believe that the integrated content we offer has an impact on participants. We have a theory of what we need to teach (competencies) and how we teach it. Our intent is that participants leave the course feeling that the overall experience may have confirmed what they know or may have challenged what they know with what they need to know. In either case, the goal is that they have been involved in the best formal devel- opment experience they have ever attended.

Being a profession will not come easily or quickly to HR. Without rigorous standards for what constitutes high-quality $H R$, without theory and research driving how $H R$ professionals think and act, and without exacting curriculum where $\mathrm{HR}$ professionals master the tools of their trade, the profession remains haphazard and indiscriminate. We hope that our work at M ichigan nudges the profession forward.

DR. W aYne Brockbank's expertise focuses on the linkages between human resource practices and business strategy, creating customer-focused organizational cultures, building competitive advantage through people, and competency development in human resource professionals. He has published widely on these topics in the H uman Resource M anagement Journal, H arvard Business R eview, H uman Resource Planning, and Personnel Administrator, and has contributed numerous book chapters. H e has consulted with private corporations on every continent. $\mathrm{H}$ is clients have included Texas Instruments, General M otors, Cathay Pacific Airways, Enron, Ford, General Electric, U nilever, Abbott Laboratories, Citicorp, Xerox, H ewlett-Packard, and Perez Companc.

DaVe U LRICH is Professor of Business Administration at The University of Michigan, where he is on the core faculty of the Michigan Executive Program, Co-Director of M ichigan's H uman Resource Executive Program, and Advanced H uman Resource Executive Program. $\mathrm{H}$ is teaching and research addresses the question: how to create an organization that adds value to customers? He studies how organizations change, build capabilities, learn, remove boundaries, and leverage human resource activities. He has generated multiple award winning national data bases on organizations, which assess alignment between strategies, human resource practices and $\mathrm{HR}$ competencies. $\mathrm{He}$ is the Editor of Human Resource $M$ anagement and serves on the editorial board of four other journals. He has published over 80 articles and book chapters.

Richard W. Beatty, Ph.D., is a Core Faculty member at The University of M ichigan's Executive $E$ ducation $C$ enter and serves as faculty member and course developer for the certification program of the American Compensation Association (Alternative Rewards and Performance $M$ easurement and $M$ anagement). As a management consultant, he has worked with well over half of the Fortune 100 firms. His specialty is working with organizations to design and implement strategic change initiatives, emphasizing the building of workforce capability (and intellectual capital) through the human resource "tool kit". He is an Associate E ditor of H uman Resource M anagement. 


\section{REFERE NCES}

Boyatzis, R. (1982). The competent manager: A model for effective performance. N ew York: John Wiley $\&$ Sons.

Brockbank, W., Ulrich, D., \& James, C. (1997). Trends in human resource competencies. Third Conference on Human Resource Competencies. Ann Arbor, M I: University of M ichigan School of Business.

Clark, K. (E d.) (1990). M easures of leadership. West O range, $\mathrm{N}$ J: Leadership Library of America.

Curry, L., \& Wergin and Associates (1993). Educating professionals: Responding to new expectations for competence and accountability. San Francisco: Jossey-Bass.

IBM /Towers-Perrin (1991). Priorities for competitive advantage, a 21st century vision: A worldwide human resources study. N ew York: Towers-Perrin.

Schoonover, S. (1998) H uman resource competencies for the year 2000: The wake-up call. Alexandria,
VA: Society of H uman Resource $M$ anagement.

Ulrich, D., Yeung, A., \& Brockbank, W. (1989). Beyond belief: A benchmark for human resources. H uman Resource M anagement J ournal, 28, 311335.

Ulrich, D., Brockbank, W., Yeung, A., \& Lake, D. (1995). H uman resource competencies: An empirical assessment. Human Resource $M$ anagement Journal, 34, 473- 495.

Ulrich, D, \& Eichinger, R. (1998, June). Human resources with an attitude. SHRM M agazine, 77-82.

Yeung, A., Brockbank, W., \& U Irich, D. (1994). Lower cost, high value: $H$ uman resources function in transition. Human Resource Planning. 17, 1-16.

Yeung, A., Woolcock, P., \& Sullivan, J. (1996). Identifying and devel oping $\mathrm{HR}$ competencies for the future: Keys to sustaining the transformation of $\mathrm{HR}$ functions. Human Resource Planning, 19, 58-65.

\section{ENDNOTES}

1. D ale Lake, then on the faculty at The U niversity of $\mathrm{M}$ ichigan, and now President of $\mathrm{H}$ uman Systems Development, was instrumental in this early research.

2. Connie James worked as project manager for the third round of data collection. Her conceptual and project management work is acknowledged and much appreciated.

3. We will use AH REP to illustrate how the HR competence work applies to our development programs since it is our capstone course; we could equally apply the principles to the other courses. 